\title{
CAPACITAÇÃO DE TÉCNICOS DE SAÚDE: UMA EXPERIÊNCIA PIONEIRA NO ESTADO DO TOCANTINS, BRASIL
}

\author{
TRAINING OF HEALTH PROFESSIONALS: A PIONEERING EXPERIENCE IN THE STATE OF \\ TOCANTINS, BRAZIL
}

\author{
Arlindo Serpa Filho ${ }^{1}$ \\ Regiane Cristina Neto Okochi ${ }^{2}$
}

Resumo Este artigo tem por objetivo socializar uma experiência vivenciada em um curso de capacitação oferecido no estado do Tocantins, Brasil, pela empresa Enerpeixe S.A., em parceria com a Secretaria de Estado da Saúde (Sesau) e o Instituto Oswaldo Cruz (IOC), da Fundação Oswaldo Cruz (Fiocruz), além de apresentar a metodologia empregada. As aulas foram ministradas por especialistas de cinco laboratórios do IOC/Fiocruz e envolveram o treinamento de agentes comunitários de saúde e técnicos de saúde de secretarias municipais e da Secretaria Estadual da Saúde do Tocantins, possibilitando a interação com profissionais-alunos em disciplinas que versavam sobre os problemas de saúde ocasionados por vetores e seus principais parasitos. A perspectiva adotada levou a uma diversidade de informações que permitiam a cada participante a compreensão do ciclo de vida do vetor e do parasito de doenças como: oncocercose, mansonelose, malária, leishmaniose, esquistossomose e doença de Chagas. Permitiu também a interação com as questões ecológicas, sanitárias e de educação ambiental. O resultado dessa capacitação proporcionou aos docentes e discentes uma experiência sobre a dimensão dos problemas de saúde no estado do Tocantins.

Palavras-chave capacitação em saúde; entomologia; malacologia; Tocantins, Brasil.
Abstract This article aims to socialize an experience in a training course offered in the state of Tocantins, Brazil, by the Enerpeixe S.A. outfit in partnership with the State Department of Health (Sesau), the Oswaldo Cruz Institute (OCI), and the Oswaldo Cruz Foundation (Fiocruz), in addition to presenting the methodology that was employed. The classes were taught by specialists from five IOC/Fiocruz laboratories and involved the training of community health workers and health professionals from municipal departments and the Tocantins State Health Department, affording interaction with the student-professionals in classes that focused on health problems caused by vectors and their major parasites. The perspective that was adopted led to a diversity of information that enabled each participant to understand the life cycle of the vectors and parasites of diseases such as onchocerciasis, mansonelliasis, malaria, leishmaniasis, schistosomiasis, and the Chagas disease. It also allowed interaction with ecological, health and environmental education issues. The training provided teachers and students with an experience on the extent of health problems in the state of Tocantins.

Keywords training in health; entomology; malacology, Tocantins, Brazil. 


\section{Introdução}

No Brasil o sistema elétrico é baseado principalmente na hidroeletricidade, onde as obras para instalação de barragens são de alto impacto ambiental. As modificações causadas pela construção das usinas hidrelétricas nas condições lóticas e lênticas são radicais e, quando aliadas ao alagamento e desmatamento, podem proporcionar aos vetores condições favoráveis para o desenvolvimento das formas imaturas e adultas.

A inundação de grandes áreas é normalmente responsável pelas modificações ambientais que frequentemente levam a alterações na distribuição e abundância da fauna de invertebrados ao longo da área de influência dos reservatórios, tanto pela supressão de hábitats quanto pela formação de novos ambientes. Dentre esses invertebrados, alguns são de interesse médicosanitário, como os dípteros das famílias: (1) Culicidae (culicíneos e anofelinos), transmissores da malária, febre amarela e dengue; (2) Psycodidae (flebotomíneos), vetores das leishmanioses; (3) Triatominae (barbeiros), vetores da doença de Chagas; (4) Simuliidae (Simulídeos), vetores da oncocercose (cegueira dos rios), mansonelose e provável desencadeador do Pênfigo Foliáceo; e (5) os moluscos de água doce (caramujos) do gênero Biomphalaria, que são responsáveis pela transmissão da esquistossomose. Ainda sobre os vetores, como os simulídeos, eles podem ter sua multiplicação favorecida devido ao superarejamento da água que sai das turbinas ou dos vertedouros, ou passa, em cascata, de um canal a outro do sistema de irrigação (Rey, 2001). O desencadeamento de focos ou surtos de doenças transmitidas por vetores, nesses empreendimentos, é um problema de saúde pública para as populações atingidas por barragens.

A insatisfação das populações locais afetadas pelas usinas hidrelétricas é fato notório e de domínio público, e a história dos atingidos por barragens no Brasil tem sido marcada pela resistência à construção delas. Esse tipo de sentimento é causado, em grande parte, pela ansiedade e medo da população em relação às rápidas alterações ambientais, à necessidade de alojamento em novas terras e moradias, ao surgimento de focos e surtos de doenças e ao aumento repentino de habitantes.

Segundo Koifman (2001), entre as principais interferências diretas e indiretas oriundas da expansão do setor elétrico nas cidades ao longo dos rios, nas comunidades ribeirinhas e em áreas indígenas, destacam-se: a realocação de comunidades para outras regiões, muitas vezes acompanhada de rupturas em seus estilos de vida; alagamento de grandes parcelas territoriais, incluindo áreas consideradas sagradas, os chamados campos santos, locais tradicionais de sepultamento; a invasão das terras indígenas, facilitadas indiretamente pela expansão das instalações do setor elétrico; a diminuição da disponibilidade da caça e a redução das áreas cultiváveis; e a proliferação 
da população de vetores, incluindo artrópodes e moluscos. Trabalhos realizados por diversos grupos têm mostrado que este panorama pode levar ao aumento na incidência de malária e outras doenças infecciosas (Arruda, 1985; Consolini et al., 1990; Bulcão, 1994; Tadei, 1994; Couto, 1996; Guimarães et al., 1997; Maia-Herzog et al., 1999). Neste contexto, os processos de degradação ambiental são intrínsecos ao cotidiano desses habitantes e se desencadeiam muito mais em função de deficiências na atuação do poder público do que devido às práticas sociais de apropriação do meio.

Koifman (2001) relata ainda sobre o número de hidrelétricas em atividade e as consequências que geram para o ambiente e para a população. Entretanto, os habitantes destas regiões não têm consciência da dinâmica social, política e econômica que os incorpora e, em muitas ocasiões, acabam assumindo a responsabilidade pelas condições ambientais insalubres, as quais são determinadas muito mais pela conjuntura sociopolítica do que pelas suas práticas sociais e tradições culturais de interação com o meio.

Neste processo, onde passam a assumir a responsabilidade pela degradação socioambiental, elaboram representações de pobreza, as quais remetem a atributos desvalorizados socialmente, tais como a falta de zelo, educação, capricho, o que resulta em uma autoimagem bastante negativa. Isto se traduz em uma representação reforçada pelo processo de exclusão social do qual são vítimas, na medida em que os segrega, afastando-os dos demais moradores, ou seja, daqueles que são assim taxados de não instruídos.

Para amenizar esse impacto e por questões ligadas às obrigações sociais e ambientais, são apresentadas soluções imediatistas que buscam o controle e erradicação dos processos erosivos, da dispersão de resíduos sólidos e da proliferação de vetores. Afinal, para a maioria dos moradores, aquele é o lugar da realização de um projeto de vida onde puderam concretizar o sonho da moradia própria e do resgate da dignidade.

Para que se iniciasse o processo de instalação e construção da usina hidrelétrica de Peixe Angical (UHE Peixe Angical), obra destinada à geração de energia elétrica localizada às margens do rio Tocantins, próximo à cidade de Peixe, no estado do Tocantins, foi necessária, como para qualquer empreendimento deste porte, a obtenção de licenciamentos exigidos pelo Instituto Nacional de Meio Ambiente (Ibama), de acordo com a resolução Conama n. ${ }^{\circ} 001$, de 23 de janeiro de 1986. Para atender a essas exigências, foram realizados Estudos de Impactos Ambientais e Relatório de Impacto no Meio Ambiente (EIA/Rima), que posteriormente foram submetidos à análise e aprovação para obtenção das licenças prévia de instalação e de operação. Antes da licença de instalação da obra, o Ibama analisa e aprova os programas ambientais derivados do Relatório de Impacto do Meio Ambiente. Dentre eles, estão os programas que abrangem saúde ambiental, em especial o Programa Ambiental de Saúde Pública, o de Monitoramento e Manejo de Fauna, que 
contemplam inúmeras ações preventivas e mitigadoras para suprir as diferentes situações do aumento da demanda ao serviço de atendimento em saúde às populações dos municípios atingidos, que, neste caso, são os de Peixe, São Valério da Natividade, Paranã, São Salvador do Tocantins e Gurupi. Estas ações pertinentes a esses programas ambientais foram realizadas na UHE Peixe Angical, no estado do Tocantins, no período de 2002 a 2007. A elaboração e execução ficaram a cargo da equipe de meio ambiente da Enerpeixe S.A., com o apoio do Consórcio Enesa Enercamp, do Consórcio Construtor de Peixe, do Instituto Oswaldo Cruz/Fundação Oswaldo Cruz, da Vigilância Sanitária Estadual de Tocantins, das secretarias estadual e municipais da Saúde de Tocantins e conselhos municipais de saúde de Peixe, São Valério da Natividade, São Salvador do Tocantins e Paranã.

Atualmente, é procedimento padrão nesse tipo de empreendimento, de acordo com a legislação do Ibama, realizar levantamentos e inventários para se conhecer a fauna de invertebrados nas regiões onde serão construídas usinas hidrelétricas, para que se possam prever possíveis alterações nos níveis populacionais de espécies presentes na área, principalmente aquelas com potencial para transmissão de doenças. Além disso, esses dados iniciais servem de base para pesquisas e monitoramento das populações de invertebrados nessas regiões.

A construção da UHE Peixe Angical, na região sul do estado do Tocantins, teve como resultado a formação de um reservatório, inundando áreas de municípios como Paranã e São Salvador do Tocantins.

Para atender às questões ambientais que podiam refletir na saúde da população da área de influência da UHE Peixe Angical e seguindo instruções e recomendações dos órgãos fiscalizadores do meio ambiente, instituições de pesquisa e universidades vêm realizando estudos que ajudam a avaliar e monitorar o impacto causado por esse empreendimento. Em convênio firmado entre a Enerpeixe S.A. e o IOC/Fiocruz, foi constatada a presença de vetores potenciais de esquistossomose, malária, febre amarela, doença de Chagas e oncocercose, que nortearam os estudos preliminares, associados ao histórico local, caracterizando a área como de risco epidemiológico permanente.

Outra vertente do convênio possibilitou a capacitação de pessoal do quadro e prestadores de serviço das secretarias municipais de Saúde do estado de Tocantins, mitigando o impacto causado pela instalação da obra através da informação transferida pelos grupos envolvidos do IOC/Fiocruz aos técnicos de saúde, a fim de que pudessem agir como multiplicadores nos municípios com potencial epidemiológico para estes agravos. Diante de tal realidade, foi proposto um curso de capacitação com características multidisciplinares voltado para a questão médico-sanitária e de estreita colaboração com outras entidades no nível local. 


\section{Metodologia utilizada para capacitação de recurso humano para saúde}

O curso de capacitação em Entomologia e Malacologia foi oferecido pelo IOC/Fiocruz, em parceira com a Enerpeixe S.A. e a Sesau-TO, no período de 25 de setembro a 3 de novembro de 2006, com carga horária de 200 horas. $\mathrm{O}$ curso obedeceu a uma estratégia de abrangência e teve como objetivo geral atualizar os conhecimentos entomológicos e malacológicos, proporcionando treinamento prático realizado em sala de aula e no campo em cada uma das cinco disciplinas.

O conteúdo deste curso destinava-se aos representantes das secretarias de saúde e a finalidade era ministrar conhecimentos pormenorizados sobre a sistemática, biologia, ecologia e importância em saúde pública das diferentes espécies de artrópodes parasitos, artrópodes veiculadores de agentes patogênicos, artrópodes hospedeiros intermediários de helmintos, artrópodes peçonhentos que acometem o homem e os animais, bem como a capacitação de agentes comunitários de saúde (ACS) para sustentação das ações de preservação ambiental, de recuperação urbana e de promoção da saúde para as populações das áreas de impactação direta ou indireta da construção da UHE Peixe Angical.

Todas as atividades foram organizadas e realizadas a partir do resgate da experiência dos grupos envolvidos, observando-se as orientações da legislação de ensino contidas na lei n. ${ }^{\circ}$ 9.394/96, a Lei de Diretrizes e Bases da Educação Nacional (LDB).

O processo de construção e implementação do curso teve início em abril de 2005, quando o projeto foi encaminhado para os diretores da Enerpeixe S.A., em atendimento a uma das cláusulas socioeducacionais do contrato de execução do projeto firmado. O passo seguinte foi organizar uma reunião com os coordenadores e subcoordenadores dos projetos do IOC/Fiocruz e a Enerpeixe S.A., visando a apresentar a estrutura organizacional do curso de capacitação e os planos de atividades para cada módulo. Nesta reunião definiu-se que o coordenador de cada grupo seria responsável pela disciplina e pela elaboração do material didático para o curso de capacitação (Quadro 1). Após a finalização da confecção do material didático, em junho do mesmo ano, este foi entregue à coordenação e gerência da Enerpeixe S.A. para posterior impressão. No mês de setembro, iniciava-se o curso com as disciplinas estruturadas, conforme descrito na Tabela 1, sendo finalizado em outubro de 2006. 
Quadro 1

Apresentação dos grupos envolvidos na capacitação com seus coordenadores e respectivos projetos desenvolvidos em colaboração com a Enerpeixe

\begin{tabular}{|c|c|c|}
\hline Grupo & Coordenador & Projeto \\
\hline Simulídeos & Dra. Marilza Maia Herzog & $\begin{array}{l}\text { "Os Simulídeos. Verificação de possíveis espécies ligadas a } \\
\text { oncocercose e ao pênfigo foliáceo, Peixe, TO". } \\
\text { Subprojeto:"Levantamento da fauna associada ao criadouro } \\
\text { de Simuliidae". }\end{array}$ \\
\hline Culicídeos & Dr. Anthony Érico Guimarães & $\begin{array}{l}\text { "Avaliação ecológica de mosquitos (Diptera: Culicidae) } \\
\text { vetores de doenças humanas em áreas de influência da } \\
\text { usina hidrelétrica de Peixe, Tocantins, Brasil. Subsídios a } \\
\text { medidas de controle". }\end{array}$ \\
\hline Triatomíneos & $\begin{array}{l}\text { Dra. Teresa Cristina } \\
\text { Monte Gonçalves }\end{array}$ & $\begin{array}{l}\text { “Avaliação ecológica de triatomíneos (Hemiptera: } \\
\text { Reduviidae) envolvidos na transmissão do agente etiológico } \\
\text { da doença de Chagas em áreas de influência da usina } \\
\text { hidrelétrica de Peixe Angical, Tocantins, Brasil. Subsídios aos } \\
\text { estudos de genética populacional". }\end{array}$ \\
\hline Flebotomíneos & Dr. Maurício Vilella & $\begin{array}{c}\text { "Estudo dos vetores das leishmanioses em área de } \\
\text { influência do aproveitamento hidrelétrico Peixe Angical, } \\
\text { estado do Tocantins. Monitoramento e subsídios } \\
\text { às medidas de controle". }\end{array}$ \\
\hline Malacologia & Dra. Silvana Thiengo & $\begin{array}{l}\text { "Avaliação da distribuição dos moluscos límnicos vetores de } \\
\text { helmintoses na área do aproveitamento hidrelétrico de Peixe } \\
\text { Angical, TO. Subsídios a medidas de controle". }\end{array}$ \\
\hline
\end{tabular}

Fonte: Os autores

As disciplinas foram realizadas em Palmas, na Sesau-TO. Cada disciplina foi ministrada por professores-pesquisadores de cinco laboratórios do IOC/Fiocruz e constaram de 20 horas de aula teórica e 20 horas de aula prática para cada módulo. O período das disciplinas realizadas no ano de 2006 (Tabela 1) foi de cinco dias consecutivos definidos conforme as disponibilidades dos profissionais indicados pelas secretarias de Saúde para participarem da capacitação (Tabela 2). A estratégia do curso em questão não permitiu um manejo grande de participantes, pois a intenção foi a de promover a participação ativa dos membros dos grupos, facilitando a recuperação e coletivização de experiências individuais nas áreas de entomologia e malacologia - lato sensu com a parasitologia. 
Tabela 1

Disciplinas ministradas com respectivos períodos da realização no ano de 2006

\begin{tabular}{lr}
\hline Disciplinas & Período \\
I - Simulídeos e fauna associada - Aspectos epidemiológicos e bioecológicos & 25-29.IX \\
II - Taxonomia e Ecologia de Culicidae & 02-06.X \\
III - Aspectos biológicos, ecológicos e epidemiológicos de triatomíneos, & 16-20.X \\
transmissores da doença de Chagas. & \\
IV - Ecologia das leishmanioses & 23-27.X \\
V - Estudos sobre moluscos & $30 . X-3 . X I$
\end{tabular}

Fonte: Os autores

Para facilitar o aprendizado do aluno, todos os módulos tiveram uma estrutura interna básica semelhante que incluiu a apresentação do tema - aula teórica, temas ou movimentos, leituras complementares e anexos, atividades de avaliação e referências bibliográficas, bem como aulas práticas, sempre ministradas no laboratório da Sesau-TO.

O texto de cada módulo foi apresentado com indicativos para atividades destinadas à reflexão, pesquisa, levantamentos para que os ACS pudessem, aos poucos, ir construindo as competências esperadas.

Com o apoio de uma apostila elaborada por módulo, buscou-se desenvolver atividades para ajudar os estudantes a identificar no texto as ideias centrais, a problematizar as ideias apresentadas e a elaborar suas próprias sínteses, registrando as conclusões à medida que avançavam no estudo do tema, além de refletir sobre sua própria experiência como agente de saúde.

Foram disponibilizados textos de leitura complementar no próprio módulo, visando a acrescentar informações acerca da aula ministrada. Mesmo não sendo leituras obrigatórias, essas referências formavam fontes de informação para que os alunos possam buscar, caso seja do seu interesse, textos para ampliar seu conhecimento a respeito daquilo que estava sendo apresentado.

O Curso de Capacitação em Entomologia e Malacologia para as secretarias estadual e municipais de Saúde do Tocantins foi elaborado para atender ao requisito de capacitação dos profissionais de saúde, um dos componentes fundamentais do projeto, que busca a participação de órgãos governamentais ligados à saúde, ao conhecimento dos vetores e às doenças transmitidas por eles, ao abastecimento de água, ao saneamento básico, dentre outros, que, com ações intersetoriais, contribuam para a redução da incidência de doenças no estado do Tocantins. 
Lembramos que a Atenção Primária à Saúde (APS), como estratégia de extensão de cobertura, e o agente de saúde, como ator nesta estratégia, estão estritamente relacionados na Declaração de Alma-Ata, que explicita:

As modalidades de agente de saúde variarão de um país e de uma comunidade para outra de acordo com as necessidades e os recursos disponíveis (...) políticas públicas deveriam financiar a iniciativa de um nível aceitável da saúde para todos os povos do mundo perto do ano 2000, que pode ser alcançado com um melhor uso dos recursos, uma parte considerável do que é agora gasto em armamentos e em conflitos das forças armadas. Uma política genuína de independência poderia e deve liberar os recursos adicionais na aceleração do desenvolvimento social e econômico proporcionando o cuidado de saúde, como uma parte essencial (Conferência Internacional..., 1979, p. 50).

O currículo desse curso foi elaborado a partir das competências a serem desenvolvidas pelos coordenadores e participantes de cada projeto em parceria com a Enerpeixe S.A. A capacitação foi desenhada para ser ofertada aos profissionais e ACS das secretarias de Saúde, aos funcionários previamente designados pela Enerpeixe S.A. e a alguns setores ligados indiretamente à área de Saúde dos municípios de São Salvador do Tocantins, Paranã, Palmeirópolis, Peixe, Gurupi e Palmas, do estado do Tocantins. A eleição dos representantes de cada município ficou por conta da coordenação da Sesau-TO, tendo como critérios a necessidade de melhorias no serviço de saúde e a proximidade do município com as doenças vetoradas por insetos e moluscos (Tabela 2).

Coube ao Programa Ambiental 22 - Saúde Pública da Enerpeixe S.A. a responsabilidade de oferecer parte da infraestrutura e logística para a realização deste curso. Foi disponibilizado transporte para os participantes, que facilitou o deslocamento de todos os ACS de suas secretarias para a cidade de Palmas, hospedagem e alimentação, bem como a impressão das apostilas para todos os módulos. Ao IOC/Fiocruz coube a elaboração e confecção do material didático e a organização, coordenação e ministrar as disciplinas oferecidas. Por parte da Sesau-TO foram oferecidos o auditório e os laboratórios para as aulas teórico-práticas.

\section{O agente comunitário de saúde}

Embora o termo genérico 'agente de saúde' chegue a ser usado na Declaração de Alma-Ata como equivalente a 'recursos humanos para atenção primária', na discussão dos atores esta designação é dada ao agente de saúde da comunidade que atua na ponta da extensão de cobertura de atenção a saúde da população: 
Ao nível inicial de contato entre os indivíduos e o sistema de serviços de saúde, os cuidados primários são proporcionados por agentes de saúde da comunidade trabalhando em equipe (Conferência Internacional..., 1979, p. 50). Outros autores falam de 'pessoal para profissional' como 'linha de frente' na extensão de cobertura (Elliot, 1984, p. 37); força de trabalho básico (...) composta de agentes de saúde da comunidade, de ori-gem local e formação modesta (Werner, 1984, p. 158); pessoal treinado não-universi-tário (...) de grande importância na pirâmide de cuidados primários em saúde porque é o contato inicial e continuado, entre população e o sistema (Chaves, 1982, p. 59).

(...) o trabalhador de saúde da comunidade "es más bien el punto central de la provisión de APS en el plano de la comunidad" (Ofosu-Amaah, 1984, p. vii).

Ainda na definição de agente de saúde, observamos a citação de Pólo (2005 apud Valentim e Kruel, 2007), que apresenta dentre os profissionais da equipe um ator de grande importância: o agente comunitário de saúde, responsável pela ligação entre a comunidade e o serviço de saúde, tendo como atribuições: visita a cada família pelo menos uma vez por mês, realização de mapeamento de sua área, o cadastramento das famílias e estímulo à comunidade à participação social. O ACS é, ao mesmo tempo, membro da equipe de saúde e da própria comunidade onde atua, sendo de suma importância a questão que envolve o histórico como morador da comunidade há pelo menos dois anos, de forma que possa conhecer as pessoas e a realidade da comunidade e ser conhecido por elas. Suas atividades são extensas e englobam desde a identificação de indivíduos e famílias expostos a situações de risco até o desenvolvimento de ações de educação e vigilância à saúde, mobilização comunitária e identificação de parceiros e recursos existentes na comunidade que possam ser potencializados pela equipe (Pólo, 2005).

Entendemos que a questão crucial do papel do ACS na conscientização, embora parta metodologicamente das questões individuais, tem por base a democratização do saber.

\section{Os frutos da capacitação}

Uma das metas estava pautada no estímulo do público-alvo em torno do binômio saúde-educação. Para atingir este objetivo, foram utilizadas técnicas como a reflexão diante dos problemas de saúde que cada um enfrenta no dia-a-dia, as quais dizem respeito a sua dinâmica social. Foram capacitados 21 profissionais e ACS pertencentes a nove municípios do Tocantins, sendo maior a presença masculina com 11 representantes (Tabela 2). Esses técnicos de saúde, designados assim por pertencerem a áreas multissetoriais de 
saúde de nível médio e superior, foram capacitados para atuar como agentes transformadores da realidade social da comunidade em que vivem. A partir do conhecimento adquirido sobre a taxonomia, biologia e ecologia dos vetores de doenças ocorrentes na área envolvida pela construção da UHE Peixe Angical, bem como os cuidados com a saúde, outros temas foram abordados, os quais levaram a discussões sobre a qualidade de vida e as possibilidades de mudança diante de novas perspectivas para essas comunidades.

\section{Tabela 2}

Qualificação dos participantes para a capacitação com número de representantes por município segundo indicação da Sesau-TO

$\begin{array}{ccc}\text { Municípios } & \text { Número de representantes } & \text { Qualificação } \\ \text { Guaraí } & 02 & \text { Agente comunitário de saúde } \\ \text { Gurupi } & 01 & \text { Técnico de saúde } \\ \text { Palmas } & 08 & \text { Técnico de saúde } \\ \text { Paranã } & 01 & \text { Técnico de saúde } \\ \text { Peixe } & 03 & \text { Técnico de saúde } \\ \text { Porto Nacional } & 02 & \text { Técnico de saúde } \\ \text { São Salvador } & 01 & \text { Agente de saúde } \\ \text { São Valério } & 01 & \text { Agente comunitário de saúde } \\ \text { Tocantinópolis } & 02 & \text { Agente comunitário de saúde }\end{array}$

As atividades didáticas teóricas e práticas de entomologia e malacologia voltaram-se para a formação desses profissionais com sustentação às ações de saúde, baseando-se nos princípios do conhecimento da taxonomia, biologia e ecologia dos vetores de doenças, da preservação ambiental e de promoção da saúde das populações envolvidas nas áreas adjacentes à UHE Peixe Angical. Em algumas disciplinas, como, por exemplo, o módulo de Simuliidae, foi possível vivenciar através da prática de campo o conteúdo assimilado nas aulas expositivas (Figuras 1, 2, 3). 
Figura 1

Aula teórico-prática na capacitação e atualização acerca dos simulídeos nas dependências

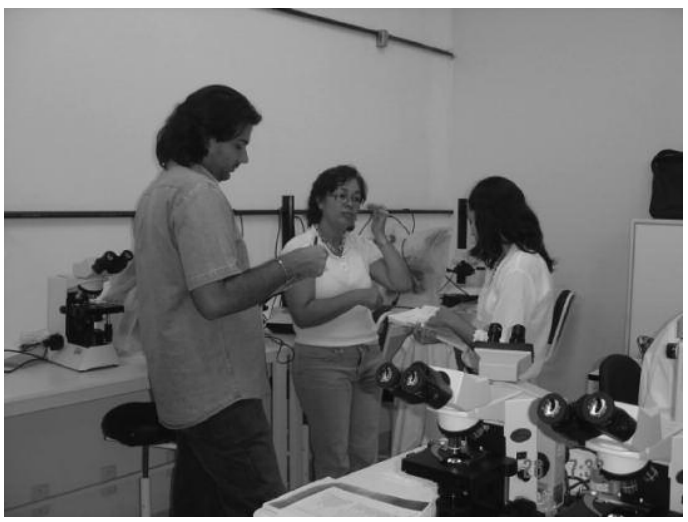

Figura 2

Aula prática na capacitação e atualização acerca dos simulídeos nas dependências da Sesau/TO em Palmas

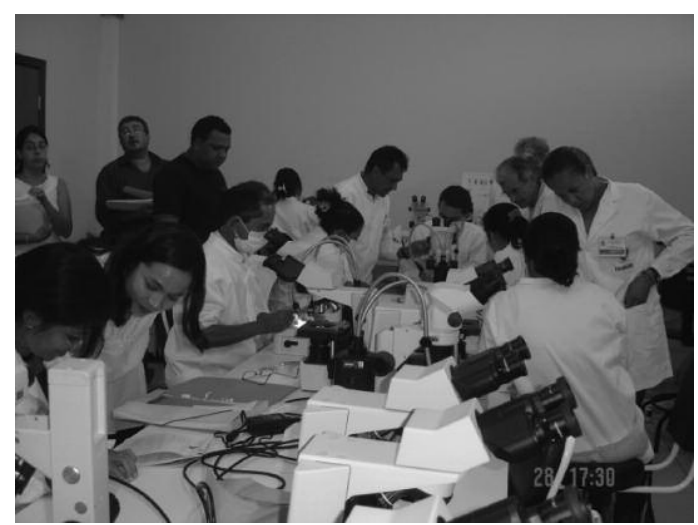

Figura 3

Confraternização entre alunos, representantes do IOC/Fiocruz, Sesau-TO e Enerpeixe S.A. nas dependências da Sesau-TO em Palmas

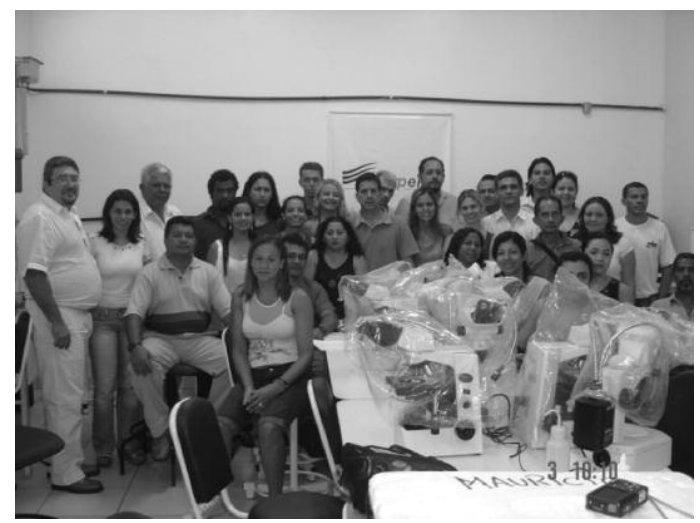


Durante o processo, todos os professores tentaram resgatar a experiência dos grupos envolvidos na construção da UHE Peixe Angical e a estreita colaboração com outras entidades no nível local. Entende-se que esse instrumento - a experiência do grupo - favoreça uma melhor compreensão das incoerências vividas no seu cotidiano pelos sujeitos - estudantes capacitados. Contudo, acredita-se que a observação participante, como as demais técnicas utilizadas na construção do objeto de estudo não reúnam condições para a apreensão integral da realidade, isto porque induz a 'explicações' elaboradas a partir de categorias interpretativas criadas pelo pesquisador, que têm como base a valorização de determinados aspectos da dinâmica social, científica e pedagógica em detrimento de outros.

Os resultados de qualquer proposta pedagógica traduzem as condições do contexto em que ela se desenvolve. No caso da capacitação em questão, precisamos considerar suas especificidades, entre elas o fato de o curso ser oferecido sem custos para os ACS e profissionais de saúde do Tocantins. Entretanto, essa análise faz sentido quando consideramos peculiaridades de nossos discentes, como o volume de atividades que executam decorrentes dos cargos que ocupam, o pouco tempo para se dedicarem ao estudo e, na maioria das vezes, a fragilidade de seus vínculos empregatícios. Se deixarmos de analisar essa realidade, em suas várias dimensões, perdemos qualquer possibilidade de qualificar nossas estratégias e decisões pedagógicas durante a elaboração e execução do curso.

Também vale comentar o fato de que todos os participantes tinham algum tempo de inserção no setor saúde, conhecimento técnico e básico sobre as políticas de saúde e a organização do sistema e dos serviços de saúde, moravam em casa própria nos bairros onde atuavam e 40\% dos representantes residiam na área onde o curso foi realizado.

\section{Discussão}

O trabalho de sensibilização e divulgação deve envolver clareza na definição do público a ser atingido e transparência na mensagem veiculada (Valentim \& Kruel, 2007).

O mercado hoje está desejoso de profissionais com qualidades distintas que sejam intensamente ativos, saibam agir, tomar decisões e usar da criatividade para solucionar problemas.

Segundo Sordi e Bagnato (1998), o que pode fazer diferença é o 'para quê e para quem' usaremos estas nossas capacidades, anteriormente adormecidas e que, ao serem despertadas, podem e devem ser postas a serviço dos interesses maiores da sociedade. 
É possível delinear estratégias que aproveitem ao máximo as potencialidades de autonomia do processo de educação, na direção de maior compromisso social e ético por parte dos egressos na área da saúde (Sordi \& Bagnato, 1998).

A proposta dentro do curso de capacitação foi formar profissionais críticos, a fim de que eles pudessem fazer parte dos discursos e das metas sugeridas pelas instituições formadoras, seguindo a proposta de Sordi e Bagnato (1998). Os mesmos autores relatam ainda que o processo pedagógico, que visa à construção do saber do indivíduo, deve estimular o ato reflexivo, desenvolvendo sua capacidade de observação, análise crítica, autonomia de pensar e de ideias, ampliando os seus horizontes, tornando-o agente ativo nas transformações da sociedade, buscando interagir com a realidade na qual está inserido.

A problemática existente na formação e no exercício da profissão na área da saúde deve ser inserida no contexto político-econômico e social, visando à contextualização, mudanças curriculares, organizacionais e reestruturações das práticas, que melhorem as condições de trabalho.

Ainda Sordi e Bagnato (1998) ressaltam que vários estudiosos assinalam que, para os futuros profissionais enfrentarem essas mudanças no mercado de trabalho, deverão possuir características e requisitos intelectuais básicos tais como autonomia, iniciativa, capacidade de resolução de problemas, criatividade, domínio da informática e de outras línguas.

No decorrer do curso, o estímulo às mudanças em várias dimensões, com a reflexão crítica dos alunos sobre suas trajetórias, foi introduzido pelos docentes envolvidos e se apresentou como uma condição necessária para quem quer transformar a maneira de pensar em educação e em saúde. Eles utilizaram suas experiências na coordenação de projetos, para atender à necessidade de promover a capacitação de profissionais, como ferramenta de atualização e aperfeiçoamento contínuo à garantia da qualidade e atenção prestadas à população. A coordenação do curso acredita que a formação do ACS não deve repercutir apenas sobre o trabalho de sala de aula, o que é uma ideia equivocada. Esta formação em saúde deve significar também valorização profissional e pessoal, uma vez que muitas vezes ele é excluído social, cultural e economicamente.

A questão abordada acima deve ser pensada de uma forma ampla, porém com mais rigor, visto que se pretende estabelecer mais comprometimento com uma formação sólida, como assinala Kuenzer (1999), e que contemple os seguintes eixos: contextual-institucional, teórico-prático e ético-investigativo.

Uma das coisas mais importantes na ação educativa em saúde é o envolvimento de várias pessoas, e o que motiva a participação, o ponto de partida, é a discussão coletiva dos problemas e das contradições existentes na realidade. Cada problema puxa um tipo de solução, para cada solução devemos procurar os melhores caminhos, pois, além do compromisso individual, é importante 
mobilizar as diversas organizações presentes em nossa realidade. Para fortalecer ou transformar a escola em um espaço de produção de saúde, precisamos de pessoas com experiência em diversas áreas do conhecimento. Além dos próprios profissionais de saúde, ACS, existem muitas raizeiras, parteiras, benzedeiras que exercem uma missão importante na saúde das populações (Brasil, 2005).

Devido à dificuldade de previsão de aparecimento de focos de endemias decorrentes das modificações no meio, causadas por grandes empreendimentos, como a construção de hidrelétricas, e a existência de situações peculiares, faz-se necessária e imprescindível a realização de estudos que visem à prevenção de doenças nas áreas afetadas, para que sejam executadas as medidas de abrandamento dos problemas que possam surgir. É importante também difundir o conhecimento da dinâmica dos vetores e as doenças por eles transmitidas.

Sordi e Bagnato (1998) ressaltam como é importante destacar que o ensino na área da saúde padece de longa data do tecnicismo, da forte biologização dos conteúdos selecionados como válidos e significativos à formação. Há sinais de luta tentando romper tal lógica, porém o ensino crítico vai precisar percorrer longo caminho, repleto de atalhos e armadilhas, até lograr algum impacto na prática.

Outro item importante dentro da parceria entre as três instituições foi a transparência, como um conceito central da responsabilidade social empresarial que caminha ao lado da atitude ética. Segundo Rico (2004), ser transparente é atender às expectativas sociais, mantendo a coerência entre o discurso e a prática e não sonegando informações importantes sobre seus produtos e serviços.

Um dos instrumentos notáveis que incentiva a atitude de comunicação transparente da empresa com os públicos com os quais se relaciona é o balanço social, prática observada a todo instante no processo desencadeado pela Enerpeixe S.A. e que vai ao encontro das ideias difundidas por Rico (2004).

\section{Considerações finais}

Entendendo saúde e educação como práticas sociais e os agentes e docentes como trabalhadores dessas áreas, o curso de capacitação procurou garantir a articulação educação-saúde no desenvolvimento dos conteúdos e na proposição de atividades. Foi possível perceber, logo nos primeiros módulos, o esforço de articular essas práticas. Tal esforço não é, entretanto, suficiente por si mesmo, cabe a nós contribuir diretamente para isso, tanto pela orientação direta a cada aluno, sempre que necessária, como pelo estímulo à organização de outros espaços de discussão e reflexão conjunta pelos alunos e 
junto a outros grupos de instituições, órgãos e empresas, interessados, igualmente, nessa articulação.

No decorrer de todo o curso, o material didático, no seu conjunto, foi aprovado pelos alunos e serviu para nortear todas as ações dentro e fora da capacitação.

O trabalho de cada equipe nos módulos com os representantes das secretarias estadual e municipais revelou que, nessas populações urbanas, a percepção da relação entre a falta de saneamento básico (por exemplo) e problemas de saúde em geral existem, assim como a percepção de que o governo deveria proporcionar esses serviços.

As atividades foram extensas, englobando desde o estudo dos vetores de doenças e a identificação de pessoas e famílias expostas a situações de risco até o desenvolvimento de ações de educação e vigilância à saúde, mobilização comunitária e identificação de parceiros e recursos existentes na comunidade que possam ser potencializados pela equipe.

\section{Agradecimentos}

À Secretaria da Saúde do Estado do Tocantins, pelo comprometimento e envolvimento na realização do curso de capacitação. À Empresa Enerpeixe S.A., pela capacidade em enxergar a importância de um trabalho contínuo em prol da valorização da saúde da população do Tocantins. A todos os professores/pesquisadores e monitores dos laboratórios do IOC/Fiocruz que participaram da capacitação. A MSc Verônica Marchon-Silva, pela revisão e contribuição ao texto. 


\section{Notas}

1 Pesquisador do Laboratório de Simulídeos e Oncocercose - Referência Nacional em Simulídeos, Oncocercose e Mansonelose, Instituto Oswaldo Cruz, Fundação Oswaldo Cruz (IOC/Fiocruz), Rio de Janeiro, Brasil. Doutor em Entomologia pelo Instituto Nacional de Pesquisas da Amazônia (Inpa). <serpa@ioc.fiocruz.br>

Correspondência: Laboratório de Simulídeos e Oncocercose - Referência Nacional em Simulídeos, Oncocercose e Mansonelose, Instituto Oswaldo Cruz (IOC), Av. Brasil, 4.365, CEP 21045-900, Pavilhão Rocha Lima, 5. ${ }^{\circ}$ andar, sala 513, Manguinhos, Rio de Janeiro, Brasil.

2 Gestora do Programa Ambiental de Saúde Pública da Enerpeixe S.A. e professora assistente da Universidade de Gurupi (Unirg), Tocantins, Brasil. Mestrado em Ciências do Ambiente pela Universidade Federal do Tocantins (UFT). < regianeokochi@bol.com.br>

\section{Referências}

ARRUDA, Mércia Eliane de. Presença de plasmódio brasilianum em macacos capturados na área de enchimento do reservatório da usina hidroelétrica de Tucuruí, Pará. Memórias do Instituto Oswaldo Cruz, Rio de Janeiro, v. 80, p. 367-369, 1985.

BEYHAUT, Graciano. Metropolização e globalização: bosquejos históricos e sociais. In: GADELHA, Regina Maria A. F. Globalização, metropolização e politicas neoliberais. São Paulo: Educ, 1997. p. 17-26.

BRASIL. Ministério da Saúde. Secretaria de Gestão do Trabalho e da Educação na Saúde. Departamento de Gestão da Educação na Saúde. A educação que produz saúde. Brasília: Ministério da Saúde, 2005. 16 p.: il. Série F. Comunicação e Educação em Saúde.

BULCÃO, José Antonio Simas. Proposta de um modelo para avaliação do impacto dos empreendimentos hidroelétricos sobre as doenças transmitidas por vetores com especial referência à malária. Dissertação (Mestrado em Medicina Tropical) - Instituto Oswaldo Cruz, Fundação Oswaldo Cruz, Rio de Janeiro, 1994.
CHAVES, Mauro M. Saúde: uma estratégia de mudança. Rio de Janeiro: Guanabara Dois, 1982.

CONFERÊNCIA INTERNACIONAL SOBRE CUIDADOS PRIMÁRIOS DE SAÚDE. AlmaAta, URSS, set. 1978. Relatório. Alma-Ata, URSS: Unicef, 1979. $32 \mathrm{p}$

Alma-Ata, URSS, set. 1978. Cuidados primários de saúde. Relatório. Alma-Ata, URSS: Unicef, 1979. p. 50.

COUTO R.C.S. Hidrelétricas e saúde na Amazônia: um estudo sobre a tendência da malária na área do lago da hidrelétrica de Tucuruí, Pará. Tese (Doutorado em Saúde Pública) Escola Nacional de Saúde Pública, Fundação Oswaldo Cruz, Rio de Janeiro, 1996.

ELLIOTT, Charles. Atenção primária é a nova prioridade?. Saúde da comunidade: um desafio. Florianópolis: Taps, 1984.

GUIMARÃES, Anthony E. Guimarães et al. Prevalência de anophelinos (Díptera Culicidae) no crepúsculo vespertino em áreas da usina hidrelétrica de Itaipu no município de 
Guaíra, estado do Paraná, Brasil. Memórias do Instituto Oswaldo Cruz, Rio de Janeiro, v. 92, p. 745-754, 1997.

KOIFMAN, Sergio. Geração e transmissão da energia elétrica: impacto sobre os povos indígenas no Brasil. Cadernos de Saúde Pública, Rio de Janeiro, v. 17, n. 2, p. 413-423, 2001.

KUENZER, Acácia Zeneida. Educação profissional: categorias para uma nova pedagogia do trabalho. Boletim Técnico do Senac, v. 25, n. 2, p.18-29, 1997.

LDB. Lei n. ${ }^{\circ}$ 9.394, de 20 de dezembro de 1996. Lei de Diretrizes e Bases da Educação Nacional. Diário Oficial da União, Brasília, p. 1-23, 23 de dez. 1996. Disponível em: $<$ www.planalto.gov.br/ccivil_03/Leis/L9394. htm>. Acesso em: 9 de jul. 2010.

MAIA-HERZOG, Marilza; SHELLEY, Anthony John; BRADLEY, Janette Elizabeth; DIAS, Antonio Paulino Andrade Luna; CALVÃO-BRITO, Regina Helena Santos; LOWRY, Christopher ; CARMAGO, Mayra; RUBIO, Jose Miguel; POST, Rory James; COELHO, Giovanini Evelim. Discovery of a new focus of human onchocerciasis in central Brazil. Transactions of the Royal Society of Tropical Medicine and Hygiene. London, v. 93, p. 235-239, 1999.

OFOSU-AMAAH, Virginia. Experiencias nacionales en el empleo de trabajadores de salud de la comunidad: exámen de algunas cuestiones y problemas actuales. Washington, D.C.: Organización Panamericana de la Salud, OMS, 1984.

PÓLO PSF. Polo de capacitação: formação e Educação Permanente de recursos humanos para Programa Saúde da Família de MaríliaSP. [Capacitação na Internet] 2005. Disponível em: <www.famema.br/saudedafamilia>. Acesso em: 9 out. 2008.
REY, Luis. Parasitologia: parasitos e doenças parasitárias do homem nas Américas e na África. 3. ed. Rio de Janeiro: Guanabara Koogan, 2001.

RICO, Elizabeth de Melo. A responsabilidade social empresarial e o Estado: uma aliança para o desenvolvimento sustentável. São Paulo em perspectiva [online], v. 18, n. 4, p. 73-82, 2004. Disponível em: <www.scielo.br/scielo. php?pid $=0102-883920040004 \&$ script $=$ sci issuetoc. >. Acesso em: 2 out. 2008.

SORDI, Mara Regina Lemes; BAGNATO Maria Helena Salgado. Subsídios para uma formação profissional crítico-reflexiva na área da saúde: o desafio da virada do século. Revista Latino-Americana de Enfermagem, Ribeirão Preto, v. 6, n. 2, p. 83-88, 1998.

TADEI, Wanderli P. Proliferação de mosquitos na hidrelétrica de Tucuruí, Pará. In: A questão energética na Amazônia: avaliação e perspectivas sócio ambientais. Anais do Seminário Internacional. 1994. p. 2-13, Belém: Núcleo de Altos Estudos na Amazônia, Universidade Federal do Pará. Museu Paraense Emílio Goeldi.

VALENTIM, Igor Vinicius Lima; KRUEL, Alexandra Jochims. A importância da confiança interpessoal para a consolidação do programa de saúde da família. Temas Livres/ Free Themes. Ciência \& Saúde Coletiva, Rio de Janeiro, v. 12, n. 3, p. 777-788, 2007.

WERNER, David. Programas rurais de saúde na América Latina. Saúde da Comunidade: um Desafio. Taps, 1984.

Recebido em 22/12/2009

Aprovado em 23/03/2010 